\title{
Patterns of Malaria: Cause-Specific and All-Cause Mortality in a Malaria-Endemic Area of West Africa
}

\author{
Heiko Becher, ${ }^{*} \dagger$ Gisela Kynast-Wolf, $\dagger$ Ali Sié, Robert Ndugwa, Heribert Ramroth, Bocar Kouyaté, and Olaf Müller \\ Department of Tropical Hygiene and Public Health, University of Heidelberg, Heidelberg, Germany; Centre de Recherche en Santé \\ de Nouna (CRSN), Nouna, Burkina Faso; Centre National de Recherche et de la Formation au Paludisme, \\ Ouagadougou, Burkina Faso
}

\begin{abstract}
Information on cause-specific mortality is sparse in sub-Saharan Africa. We present seasonal patterns of malaria and all-cause mortality from a longitudinal study with 60,000 individuals in rural northwestern Burkina Faso. The study is based on a demographic surveillance system and covers the period 1999-2003. Overall, 3,492 deaths were observed. Cause of death was ascertained by verbal autopsy. Age-specific death rates by cause and month of death were calculated. Seasonal and temporal trends were modeled with parametric Poisson regression. Infant and children less than 5 years of age mortality was 60.6 (95\% CI, 56.2-65.3) and 31.9 (95\% CI, 30.4-33.5) per 1,000 for all causes and $23.4(95 \%$ CI, 20.7-26.4) and 13.3 (95\% CI, 12.3-14.3) for malaria, respectively. Mortality was significantly higher in the rainy season. It is well described parametrically with a sinusoidal function. In adults, the highest all-cause mortality rates were observed in the dry season. Here, HIV/AIDS has become a leading cause of mortality.
\end{abstract}

\section{INTRODUCTION}

Mortality in developing countries. There are continuing high rates of infant and childhood mortality in the poor populations of the developing world. ${ }^{1,2}$ Worldwide, 10.8 million children under the age of 5 years die each year. Although childhood mortality rates have been slightly decreasing in many developing countries over the last decades, ${ }^{3}$ they are still in the order of 50-100 per 1,000 person-years in a number of countries, thus being up to 50 times higher than in the industrialized parts of the world. ${ }^{4}$ Well-known main causes of childhood death include pneumonia, diarrhea, malaria, HIV/ AIDS, undernutrition, a combination of these, and others, with large local and regional variations. 5,6

Unlike childhood mortality, adult and old-age mortality in developing countries has not been a major research focus. Available data have shown, however, that the mortality rate ratios are not as extreme as for infants and children but that there are higher mortality rates in all age groups in developing countries compared with developed countries. ${ }^{7}$ In adults, HIV/AIDS is the most frequent cause of death in many parts of sub-Saharan Africa (SSA), but also non-communicable diseases and non-natural causes of death are already playing a major role. ${ }^{4}$

Demographic surveillance systems and verbal autopsy method. In most countries of SSA, no vital registration systems are available, and most deaths occur at home. ${ }^{1,8-11}$ The ascertainment of cause of death is largely based on verbal autopsy (VA), in which the most likely cause of death is determined based on postmortem interviews with family members about the circumstances leading to death and the symptoms and signs seen before death. This information is independently evaluated by experienced physicians. ${ }^{12} \mathrm{De}-$ spite obvious limitations, verbal autopsies are at present the best possible method to obtain reasonably precise information on cause-specific deaths in poor countries. ${ }^{13-16}$ Among the limitations of the method are an often large percentage of deaths with unknown cause, resulting either from completely

\footnotetext{
* Address correspondence to Heiko Becher, INF 324, 69120 Heidelberg, Germany 69120. E-mail: heiko.becher@urz.uni-heidelberg.de $\dagger$ Both authors contributed equally.
}

missing information from the relatives or from insufficient information that led to conflicting evaluations from the physicians. Moreover, because of overlapping signs and symptoms among prevalent diseases (e.g., malaria and pneumonia in childhood), the VA method often lacks specificity. ${ }^{16,17}$

In addition to these obstacles, the field procedures of the VA are far from uniform. To improve this, an increasing number of demographic surveillance systems (DSSs) are being established under the auspices of the International Network of field sites with continuous Demographic Evaluation of Populations and Their Health in developing countries (INDEPTH) Network. ${ }^{18}$ In these systems, a population is under constant demographic surveillance, which allows estimating mortality rates and other health-related parameters more precisely.

Cause-specific mortality in SSA. Cause-specific mortality rates in SSA have been presented only in a few studies. Most of these are based on VA methodology within DSS populations and most are in populations of children. Among these are studies from The Gambia, ${ }^{19}$ South Africa and Senegal, ${ }^{13,20}$ Tanzania, ${ }^{7}$ Ghana, ${ }^{21}$ Nigeria, ${ }^{22}$ and Burkina Faso. ${ }^{23}$ Recently, a summary analysis of 12 DSS sites has been published. ${ }^{24}$ In this publication, large differences in causes of death not only between the southern, eastern, and western parts of SSA, but also within countries (Burkina Faso, Ghana, and Senegal), have been reported. Such differences were observed both in children and in adults. In these three West African DSS sites, however, malaria was the most frequent reported cause of death in children. ${ }^{24}$

Seasonal patterns of mortality. There are few studies from SSA in which seasonal patterns of mortality are reported. Among the few are studies from Senegal, ${ }^{13,25}$ The Gambia, ${ }^{19,26}$ and Nigeria, ${ }^{27}$ which are mainly on childhood mortality. The shortage of publications on the seasonal pattern in mortality is most notable for adults. ${ }^{28}$ Slightly higher mortality rates in adults were observed during the rainy season compared with the dry season in a study from rural SSA. ${ }^{29}$

Seasonal trends in adults and older people of all-cause mortality in rural Burkina Faso were first discussed for 19931998 , based on data from the Nouna DSS. ${ }^{30}$ Seasonal patterns of overall mortality in the same population were analyzed for the period 1993-2001 for all age groups, observing an excess 
of mortality in young children at or around the end of the rainy season in contrast to an excess mortality in older children and adults during the early dry season. ${ }^{31} \mathrm{~A}$ first analysis of Nouna DSS data regarding cause-specific mortality by season in young children ascertained higher rates in the rainy than the dry season with malaria as the most frequent diagnosis ${ }^{23}$ which is in line with the statement that almost a third of the annual mortality in this age group is attributable to malaria. ${ }^{32,33}$

In this paper, we present a detailed analysis of causespecific mortality in different age groups of the Nouna DSS area in rural Burkina Faso. This includes a thorough analysis of the seasonal patterns of malaria mortality.

\section{MATERIALS AND METHODS}

Study area. The database for this study is based on a DSS run by the Center de Recherche en Santé de Nouna (CRSN) in the Nouna Health District, which is described in detail elsewhere. ${ }^{34}$ In brief, the Nouna DSS covers a large part of Kossi province in northwestern Burkina Faso (a landlooked country in the Sahel zone of SSA): 41 villages and-as of 2000 - Nouna town, which is the capital city of the Nouna Health District. The study area had $\sim 62,000$ inhabitants in 2003. The first baseline census took place in 1992 and collected demographic information on all individuals in the study area. Two control censuses were held in 1994 and 1998 to check and add information in comparison to previous censuses. The data collection and vital event registration follows a 3-month cycle. Subsistence farming is the main socioeconomic activity of the multiethnic population. Health services in the DSS area make up the District Hospital in Nouna town and six local health centers in the surrounding villages.

The Nouna area is a dry orchard savannah. Malaria is holoendemic in the Nouna study area. ${ }^{23}$ Malaria transmission and disease peak during and shortly after the rainy season, which usually lasts from June until October. The overall annual entomologic inoculation rate (EIR) varies between 100 and 900 per year, with $\sim 95 \%$ occurring in the wet season. ${ }^{35}$

Study population and cause of death assessment. Data were analyzed for the period January 1, 1999 to December 31, 2003. Although the rural area encompasses the whole time period, the Nouna town population could only be analyzed from January 1, 2000.

The causes of death are determined by the VA method. VA data are collected by trained field staff who systematically visit the households of deceased persons in the CRSN study area. The VA is conducted after the interviewer confirms a death, but in most cases not sooner than 3 months after the death has occurred to allow for the mourning period. The form used includes individual identification information retrieved from the DSS. A standardized questionnaire, developed at CRSN in a collaborative process with other INDEPTH sites, ${ }^{18}$ is applied after having obtained oral informed consent.

The questionnaire covers demographic data and the clinical history before the death occurred. Approximately $5-10 \%$ of these questionnaires are systematically checked by the supervisors of field staff through field visits and repeated interviews. These questionnaires are read by two experienced local physicians out of a pool of locally available and specifically trained physicians who assign a definite cause of death. Two physicians code the completed questionnaires. After assessing all the information collected onto the questionnaire by a fieldworker, the first physician, to the best of his knowledge on the clinical field, provides the most likely cause of death. A second physician completely blinded of the diagnosis of the first one provides the cause of death through the same process. Where the diagnoses are different, a third physician who is not blinded of the diagnoses of the first two physicians gives an independent assessment. A cause of death is determined if at least two of the medical doctors agree; otherwise, the cause is classified as unknown. As for the other causes of death, malaria is attributed according to best clinical knowledge of the physician based on the main malaria symptoms: acute fever, vomiting, headaches, convulsion, and impair consciousness in a febrile context.

Statistical methods. All individuals with a residence period in the study area within the study period were included in the analysis. A few individuals with a missing month of death $(N=17)$ were excluded for all analyses concerning month of death.

For each month within the study period, the monthly population $N_{i j k l}$ by sex $(i=0,1)$, age group $(j=1, \ldots, 5)$, year $(k=1999, \ldots, 2003)$, and month $(l=1, \ldots, 12)$ was calculated as the arithmetic mean of the population at the beginning and the end of a given month. We considered age groups as follows: infants $(<1$ year, $j=1)$, children $(1$ to $<5$ years; $j=2$ ), youth (5 to $<14$ years; $j=3$ ), adults $(15$ to $<60 ; j=$ $4)$, and old people $(60+$ years; $j=5)$. Likewise, the total number of deaths in these categories were calculated and denoted by $D_{i j k l}$. For a cause-specific analysis, we considered malaria $(m=1)$, other causes $(m=2)$, and ill-defined and missing causes $(m=3)$; thus, $D_{i j k l}=D_{i j k l 1}+D_{i j k l 2}+D_{i j k l 3}$. For some analyses, infants and children and/or both sexes were combined. Mortality rates and cause-specific mortality rates were calculated as $\mu_{i j k l}=D_{i j k l} / N_{i j k l}$ and $\mu_{i j k l m}=D_{i j k l m}$ ' $N_{i j k l}$, respectively. Rates were expressed per 1,000 and multiplied by 12 to allow comparison to yearly rates. To show the relevance of diseases by month, the proportion of causespecific deaths relative to all deaths in that month was calculated.

For graphical assessment of time trends and seasonal patterns, we used a simple 5-month simple moving average (MA) with weights according to

$$
\begin{aligned}
\mathrm{MA}_{\text {month }}= & 0.4 \times \mu_{\text {month }}+0.2 \times\left(\mu_{\text {month }+1}+\mu_{\text {month }-1}\right) \\
& +0.1 \times\left(\mu_{\text {month }+2}+\mu_{\text {month }-2}\right) .
\end{aligned}
$$

For assessing the relative effect of each month on overall or cause-specific mortality, we fitted Poisson regression models separately by age group. For the former, we fitted the models

$$
\ln \left(\mu\left(x_{1}, x_{2}, x_{3}\right)\right]=\beta_{1}^{\prime} x_{1}+\beta_{2} x_{2}+\beta_{3} x_{3}
$$

and

$$
\ln \left[\mu\left(x_{2}, x_{3}\right)\right]=\beta_{0}+\beta_{2} x_{2}+\beta_{3} x_{3} .
$$

In Model $\mathrm{I}, x_{1}$ is a vector with binary dummy variables for each month, $x_{2}$ is a binary variable for sex, and $x_{3}$ represents calendar year; Model I has no intercept and provides an estimate for each month, i.e., $\beta_{1}^{\prime}=\left(\beta_{1 \text { Jan }}, \beta_{1 F e b}, \ldots, \beta_{1 \text { Dec }}\right)$. In Model II, an intercept $\beta_{o}$ instead of a monthly effect is estimated. The relative effect of each Month $l$ on mortality is expressed by the difference $\beta_{1 l}-\beta_{0}$ of the monthly effect of Model I and the overall effect of Model II. ${ }^{36}$

For continuous modeling of the seasonal trend, we used a 
TABLE 1

Most frequent causes of death by age groups, Nouna DSS, 1999-2003

\begin{tabular}{|c|c|c|c|c|c|c|c|c|c|c|c|c|c|c|c|}
\hline \multirow[b]{2}{*}{ Rank } & \multicolumn{3}{|c|}{ Infants $(<1$ year $)$} & \multicolumn{3}{|c|}{ Children (1-4 years) } & \multicolumn{3}{|c|}{ Young age (5-14 years) } & \multicolumn{3}{|c|}{ Adults (15-59 years) } & \multicolumn{3}{|c|}{ Old age ( $\geq 60$ years) } \\
\hline & & $N$ & Percent & & $N$ & Percent & & $N$ & Percent & & $N$ & Percent & & $N$ & Percent \\
\hline 1 & Malaria & 265 & 38.6 & Malaria & 408 & 43.8 & Malaria & 59 & 26.1 & HIV/AIDS & 132 & 17.2 & Malaria & 164 & 18.6 \\
\hline 2 & Neonatal & 80 & 11.7 & AGI & 124 & 13.3 & Accident & 20 & 8.9 & ARI & 53 & 6.9 & ARI & 122 & 13.9 \\
\hline 3 & ARI & 50 & 7.3 & ARI & 52 & 5.6 & AGI & 14 & 6.2 & Malaria & 49 & 6.4 & AGI & 86 & 9.8 \\
\hline 4 & AGI & 42 & 6.1 & Malnutr & 24 & 2.6 & ARI & 8 & 3.5 & Cardio & 41 & 5.3 & Cardio & 68 & 7.7 \\
\hline 5 & Men & 19 & 2.8 & HIV/AIDS & 19 & 2.0 & HIV/AIDS & 8 & 3.5 & AGI & 31 & 4.0 & Tub & 15 & 1.7 \\
\hline \multirow[t]{5}{*}{6} & Pert & 5 & 0.7 & Accident & 18 & 1.9 & Men & 5 & 2.2 & Maternal & 31 & 4.0 & Accident & 14 & 1.6 \\
\hline & Others & 28 & 4.1 & Others & 60 & 6.5 & Others & 34 & 15.0 & Others & 149 & 19.4 & Others & 83 & 9.4 \\
\hline & Ill-def. & 31 & 4.5 & Ill-def. & 31 & 3.3 & Ill-def. & 18 & 8.0 & Ill-def. & 75 & 9.8 & Ill-def. & 107 & 12.2 \\
\hline & Missing & 166 & 24.2 & Missing & 195 & 21.0 & Missing & 60 & 26.6 & Missing & 208 & 27.0 & Missing & 221 & 25.1 \\
\hline & Total & 686 & 100.0 & Total & 931 & 100.0 & Total & 226 & 100.0 & Total & 769 & 100.0 & Total & 880 & 100.0 \\
\hline
\end{tabular}

sine function of the form $g\left(x_{1}\right)=\sin [($ month $+k) \times \pi / 6]$, assuming a period of 12 months, where $k$ can take a real value between 1 and 6 and. This results in the model

$$
\ln \left[\mu\left(x_{1}, x_{2}, x_{3}\right)\right]=\beta_{0}+\beta_{1} g\left(x_{1}\right)+\beta_{2} x_{2}+\beta_{3} x_{3} .
$$

(Model III)

The value $k$ that gives the best fit is obtained numerically. The difference of deviances between Models II and III is asymptotically $\chi^{2}$ distributed with two degrees of freedom, because two parameters $\left(k, \beta_{1}\right)$ are estimated. Effects are given as logarithmic rate ratios (RRs).

All analyses were carried out with SAS (SAS, Cary, NC) ${ }^{37}$; the Poisson regression used the SAS-procedure PROC GENMOD.

\section{RESULTS}

During the observation period of January 1, 1999 to December 31, 2003, a total number of 3,492 deaths were recorded. A VA questionnaire was completed for $75.5 \%$ of all deceased persons. Few VAs $(<5 \%)$ were done within $0-3$ months after death, because the mourning period after death does not allow this. Because the vital event registration follows a 3-month cycle, $\sim 50 \%$ of VAs were performed within 2-4 months after death and $\sim 50 \%$ within 4-6 months after death. Although the numbers of missing cause of death are very similar for all five age groups, the numbers of ill-defined causes of death resulting from insufficient or unclear information are relatively small $(\sim 7.5 \%)$ but increase with age.

Table 1 gives an overview of the most frequent causes of death in the different age groups. Malaria was the main cause of death in all age groups except adults. Here, HIV/AIDS was the most frequent cause of death. Other main causes of death were acute respiratory infections (ARIs) and acute gastrointestinal infections in all age groups, neonatal causes in infants, accidents in older children, and cardiovascular and maternal causes in adults.

The population size (as of December 31 of each year) increased steadily from 60,936 in 2000 to 62,686 in 2003, which was an average yearly increase of $0.95 \%$. In 1999 , the population was 34,326 , because the town of Nouna was not yet included. The crude mortality rate for the overall population was 12.6 per 1,000 person-years (95\% CI, 12.2-13.0).

For all causes, the mortality rate for infants was $60.5 / 1,000$ (95\% CI, 56.2-65.3), for children 1-4 years of age, it was 23.6/1,000 (95\% CI, 22.2-25.2), for children 5-14 years of age, it was $2.8 / 1,000$ (95\% CI, 2.4-3.2), for adults $15-59$ years of age, it was 5.9/1,000 (95\% CI, 5.5-6.3), and for people $\geq 60$ years of age, it was 54.7/1,000 (95\% CI, 51.0-58.3; Table 2). The mortality rate in children younger than 5 years of age was 31.9 (95\% CI, 30.4-33.5). For malaria, the mortality rate was 23.4/1,000 (95\% CI, 20.7-26.4) for infants, 10.4/1,000 (95\% CI, 9.4-11.4) for children 1-4 years of age, 0.7/1,000 (95\% CI,

TABLE 2

Deaths, percentage malaria of all deaths, and death rates per 1,000 by age groups for all causes by month, Nouna DSS, 1999-2003

\begin{tabular}{|c|c|c|c|c|c|c|c|c|c|c|c|c|c|c|c|}
\hline \multirow[b]{2}{*}{ Month } & \multicolumn{3}{|c|}{ Infants $(<1$ year $)$} & \multicolumn{3}{|c|}{ Children (1-4 years) } & \multicolumn{3}{|c|}{ Young (5-14 years) } & \multicolumn{3}{|c|}{ Adults ( $15-59$ years) } & \multicolumn{3}{|c|}{ Old age ( $\geq 60$ years) } \\
\hline & $N$ & $\%$ mal & Rate & $N$ & $\% \mathrm{mal}$ & Rate & $N$ & $\%$ mal & Rate & $N$ & $\%$ mal & Rate & $N$ & $\%$ mal & Rate \\
\hline Jan & 46 & 34.4 & 51.5 & 77 & 42.6 & 24.4 & 12 & 50.0 & 1.9 & 47 & 14.8 & 4.6 & 93 & 40.0 & 73.3 \\
\hline Feb & 32 & 54.2 & 34.7 & 62 & 30.4 & 18.9 & 22 & 29.4 & 3.3 & 73 & 5.8 & 6.7 & 74 & 26.5 & 55.4 \\
\hline Mrc & 50 & 48.5 & 53.9 & 44 & 64.7 & 13.4 & 20 & 0.0 & 3.0 & 77 & 4.5 & 7.1 & 84 & 26.0 & 62.9 \\
\hline Apr & 44 & 50.0 & 47.5 & 62 & 45.5 & 18.9 & 24 & 35.3 & 3.6 & 71 & 11.4 & 6.5 & 116 & 31.4 & 86.9 \\
\hline May & 44 & 44.4 & 47.4 & 54 & 73.2 & 16.4 & 13 & 28.6 & 2.0 & 57 & 14.7 & 5.2 & 76 & 27.3 & 56.9 \\
\hline Jun & 33 & 50.0 & 35.3 & 49 & 50.0 & 14.9 & 10 & 16.7 & 1.5 & 63 & 5.0 & 5.8 & 60 & 36.1 & 44.9 \\
\hline Jul & 48 & 52.6 & 51.0 & 57 & 55.3 & 17.3 & 13 & 75.0 & 2.0 & 44 & 10.3 & 4.0 & 53 & 22.9 & 39.5 \\
\hline Aug & 99 & 75.0 & 104.0 & 88 & 73.7 & 26.7 & 23 & 37.5 & 3.5 & 72 & 17.3 & 6.6 & 50 & 39.4 & 37.2 \\
\hline Sep & 74 & 70.2 & 77.8 & 97 & 72.0 & 29.4 & 14 & 30.0 & 2.1 & 54 & 8.3 & 4.9 & 59 & 16.7 & 43.8 \\
\hline Oct & 74 & 56.1 & 77.4 & 123 & 67.3 & 37.1 & 23 & 40.0 & 3.4 & 74 & 8.2 & 6.7 & 61 & 26.2 & 45.2 \\
\hline Nov & 84 & 46.3 & 87.8 & 117 & 50.6 & 35.3 & 25 & 62.5 & 3.7 & 56 & 12.5 & 5.1 & 66 & 33.3 & 48.7 \\
\hline Dec & 52 & 41.0 & 54.6 & 102 & 53.3 & 30.7 & 23 & 56.3 & 3.4 & 79 & 12.5 & 7.2 & 82 & 28.0 & 60.4 \\
\hline Total & 680 & 38.8 & 60.5 & 932 & 44.0 & 23.6 & 222 & 25.7 & 2.8 & 767 & 65.2 & 5.9 & 874 & 18.6 & 54.5 \\
\hline
\end{tabular}

$N$, all deaths; \%mal, percent malaria of all known deaths. 
0.5-0.9) for children 5-14 years of age, 0.4/1,000 (95\% CI, $0.3-0.5$ ) for adults $15-59$ years of age, and 10.2/1,000 (95\% CI, 8.6-11.7) for people $\geq 60$ years of age. The mortality rate in children younger than 5 years of age was 13.3/1,000 (95\% CI, 12.3-14.3).

Table 2 shows the number of deaths and respective mortality rates by months and age groups. Seventeen of the 3,492 deceased persons with a missing month of death were omitted here. For infants, August, being in the middle of the rainy season, was the month with the highest rate of mortality $(104.0 / 1,000)$, whereas for children, it was October (37.1/ $1,000)$, which is at the end of the rainy season. The percentage of malaria in infants and children among all deaths was highest during the rainy season, whereas this is less clear for the other age groups.

Figure 1 shows the relative effect of month of death as obtained from the Poisson regression model for three of the defined age groups: infants ( $<1$ year), children (1-4 years), and people $\geq 60$ years old. The age groups 5-14 and 15-59 years were not further considered because, in the former age group, too few deaths for a particular cause occurred for further modeling. In the top part of Figure 1, all-cause mortality is presented. Here, children and infants showed higher relative rates in the months of the rainy season, whereas people $\geq 60$ years of age had a trend in the opposite direction. In the bottom part of Figure 1, we present malaria mortality as the main cause of death for these age groups. The patterns are similar, but the relative effect is stronger, showing that malaria is the underlying cause for the pattern: again, infants and children showed higher mortality rates from August until November (i.e., during and shortly after the rainy season), whereas the people $\geq 60$ years of age had the highest rates from January to April in the dry season.

To further assess the effect of season on mortality, rates were modeled as a continuous function of month using the Poisson regression. Figure 2 shows the RRs for each month and the sine function describing the RRs depending on month for the same three age groups and for malaria and all other causes of death. Both infants and children 1-4 years of age had highly significant seasonal trends, with higher rates from

\section{All-causes of death}

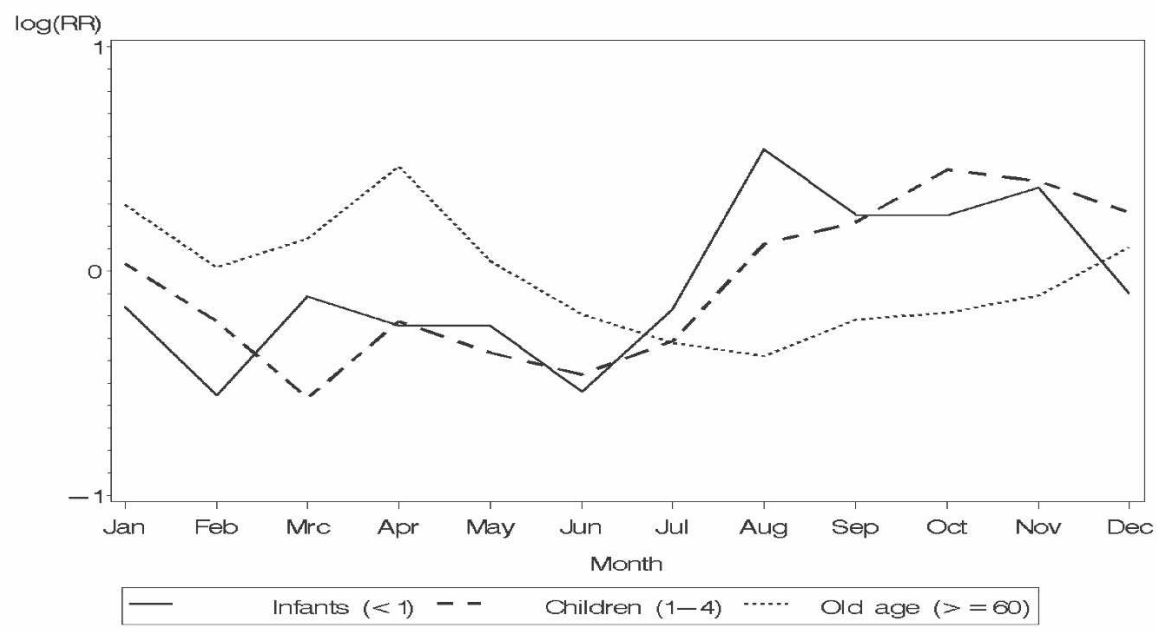

Malaria

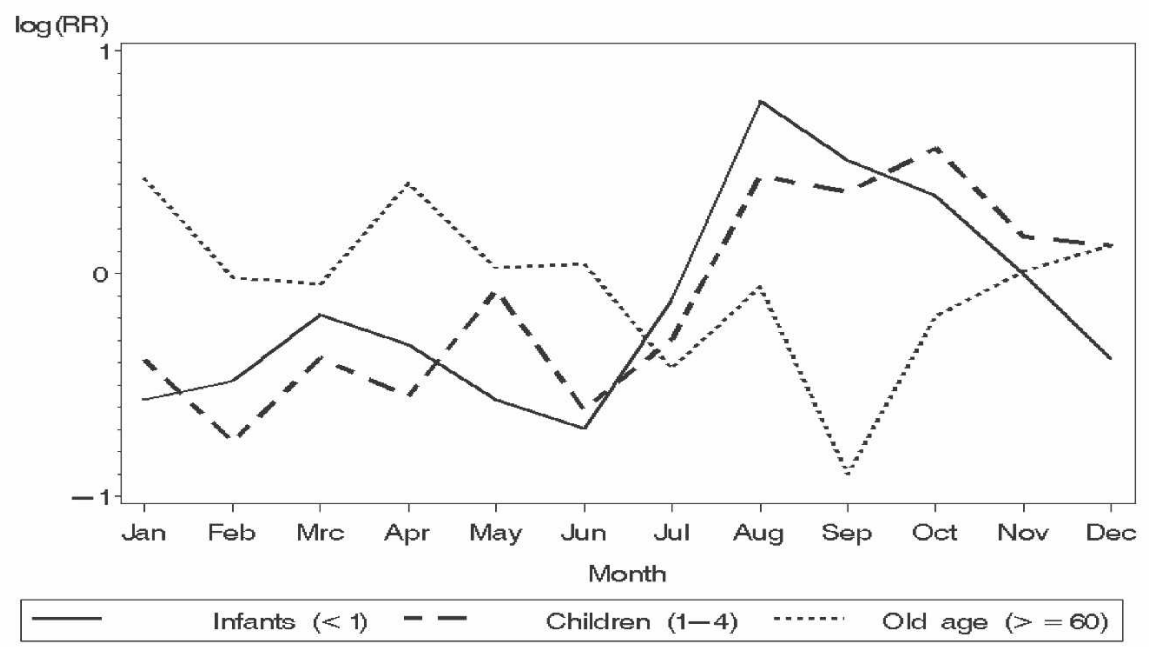

FIGURE 1. Relative effect of month of death by age group, Nouna DSS, 1999-2003. 
Infants $(<1$ year $)$

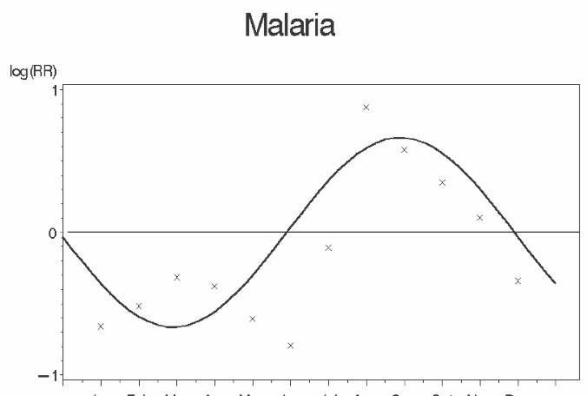

Jan Feb Mrc Apr May Jun Jul Aug Sep Oct Nov Dec
Other diseases

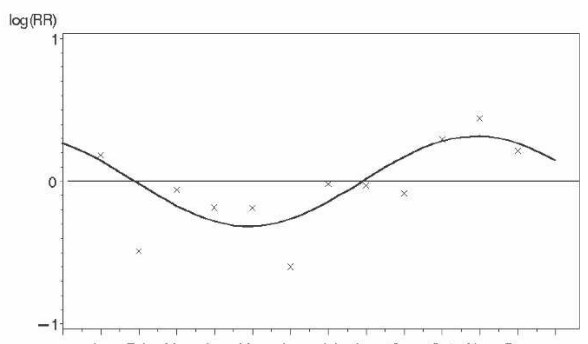

Jan Fob Mre Apr May Jun Jul Aug Sep Oct Nov Dec

\section{Children (1-4 years)}


\section{Old aged people (above 60 years)}
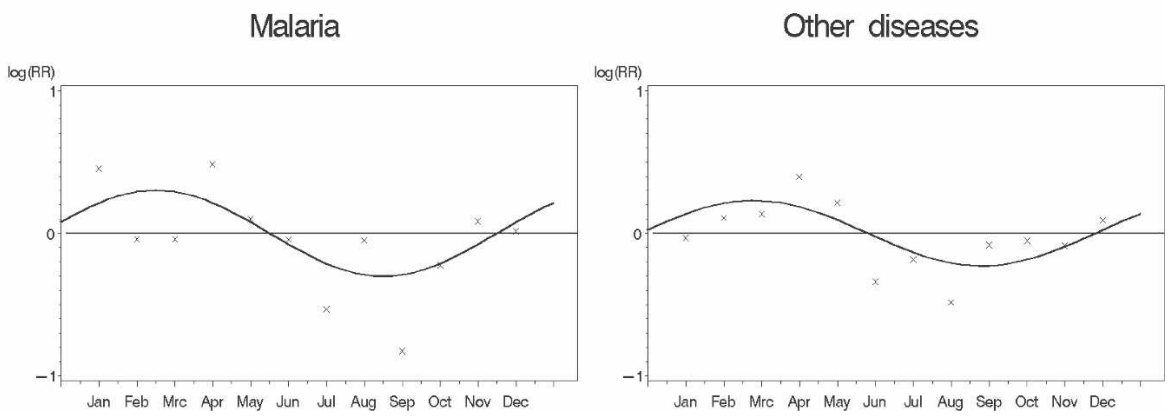

FIGURE 2. Rate ratios by month of death, Nouna DSS, 1999-2003. Continuous (solid line) and discrete $(\times)$ rate ratios, Poisson regression, adjusted for sex, area, and calendar year.

August until November for malaria $(P<0.0001)$. For other diseases, higher rates occurred in the dry season from October until February $(P=0.005$ in infants and $P<0.0001$ in children). Because in our analysis, several causes of death were combined, because of limited numbers, an interpretation with regard to climatic conditions does not seem appropriate. The highest rates (model based) for people $\geq 60$ years of age for malaria were in $\operatorname{March}(P=0.03)$. The same seasonal pattern was observed for all other diseases $(P=$ 0.006).

In Figure 3, the monthly mortality rates, the result from modeling a sine function, and the moving average of the mortality rates are graphical shown over the whole observation period. In this analysis, all children younger than 5 years of age are combined to increase sample size. It is presented for malaria and other diseases. For malaria, we observe a very similar pattern over the observation period. Highest malaria rates were observed in the rainy season of the last year of observation (2003), but there was no clear trend over the observation period. The corresponding parameter $\beta_{3}$ was not significant in any of the models. There was no effect of sex, indicated by a parameter $\beta_{2}$ close to zero, for malaria, but we observed a significant low risk for other diseases in women $(\mathrm{RR}=0.8, P=0.01)$. The model-based malaria mortality estimate and the moving average visually showed a very similar result, further supporting the modeling approach. There was also a clear mortality pattern for other disease mortality, with a peak in December and the lowest rate in June. Again, 

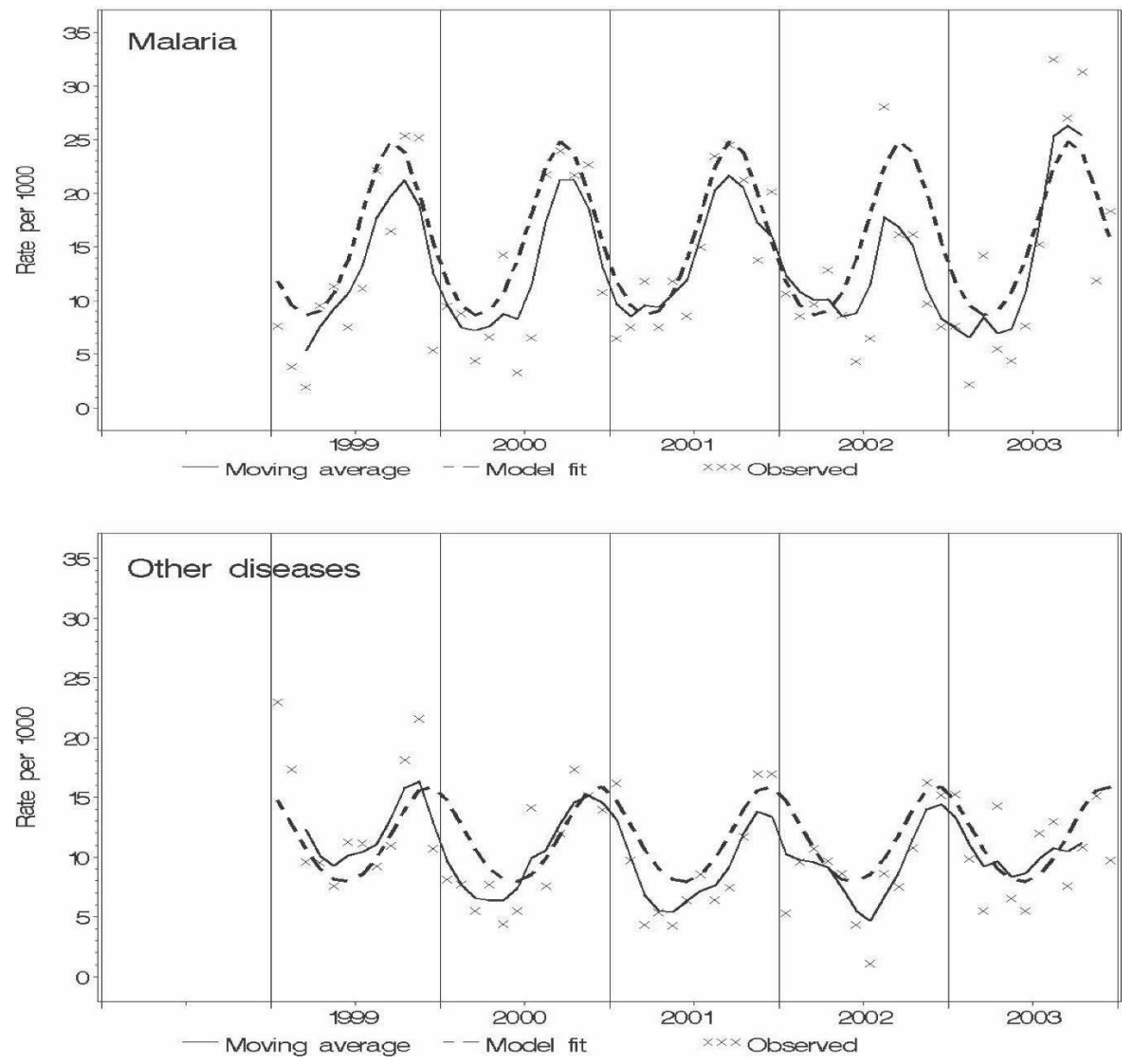

FIgURE 3. Mortality rates by cause of death for children less than 5 years of age by year, Nouna DSS, 1999-2003. Continuous modeling by Poisson regression (dashed line), moving average (solid line), and empirical rates. Other diseases means deaths with known cause.

the model-based estimate and the moving average showed a very similar result.

\section{DISCUSSION}

Seasonal pattern of mortality. We showed in this paper that the previously reported seasonal pattern in all-cause mortality in children younger than 5 years of age in Burkina Faso is to a large extent attributable to malaria. There was a consistent pattern of mortality over the 5-year observation period, with the peak of malaria mortality always toward the end of the rainy season (the period of maximum malaria transmission intensity), which can be modeled by a sinusoidal curve. Although not significant, the same pattern is seen in older children (data not shown). The pattern of mortality in adults and old-aged people show the opposite direction, with highest mortality rates in the dry season. To our knowledge, the modeling of seasonal patterns of malaria and other disease mortality with a parametric sinusoidal function has not been done previously. We checked the validity of this approach graphically by comparing a moving average of the rates. We think this is a useful procedure to describe patterns of mortality.

The interpretation that the frequent diagnosis of malaria in old-aged people is most likely related to the limitations of the $\mathrm{VA}$ instrument is further supported by the non-plausibility of a peak in malaria deaths in the dry season (see below).

Causes of death. The results from this study also confirm the major importance of malaria as cause of death in the rural malaria endemic areas of SSA. ${ }^{1,8,14,23,24,38-40}$ The data furthermore confirmed the high proportion of malaria deaths among the still unacceptably high number of childhood deaths in SSA. ${ }^{14,23,24,41}$ However, although it is rather plausible that malaria is the major cause of mortality in young children living in an area of high malaria transmission intensity, the finding that it is also the major cause of death in older children (5-14 years) and in older adults ( $>60$ years) is surprising and is likely explained by the limitations of the VA instrument (see below).

Besides malaria, ARI and gastrointestinal infections were shown to be other important causes of deaths in all age groups, which confirms global estimates and supports the view of these diseases are neglected causes of mortality. ${ }^{1,42}$ Other important causes of death seen in this study were neonatal causes in infants and accidents in older children, supporting the increasing importance of these causes in developing countries. ${ }^{1,4}$ Finally, HIV/AIDS has already become the primarily diagnosed cause of death in adults in this rural SSA area. Although HIV prevalence is still not very high in rural Burkina Faso, the fact that many young men of the study area have returned from urban centers of West Africa, where they went for work, may partly explain these observations. This supports the high impact of the HIV/AIDS epidemic in all countries of SSA these days. ${ }^{4}$

Study limitations. Our study has some limitations. A drawback in our data is the high percentage of deaths with missing information on cause or insufficient data to assign a likely 
cause of death in the VA procedure. This is, however, a problem of most similar studies from SSA. It is difficult to make assumptions on the missing mechanism. If we assume missing at random, this would imply an underestimation of the causespecific rates for all causes, and an adjustment would be crudely possible by multiplying each rate by the factor $1 /(1-$ $\left.p_{\text {miss }}\right)$, where $p_{\text {miss }}$ is the proportion of missing values in the respective age group. For example, this yields a factor of $1 /(1$ $-0.21)=1.26$ for the age group "children $1-4$ years." We did not use this procedure because the missing at random assumption cannot be verified and may be questionable. It is, however, likely that the missing value cases include malaria deaths and that the malaria rates are therefore underestimated. This would also imply that the amplitude of the sinus model fit would be higher.

A further limitation relates to the VA method itself. Malaria diagnosis is one of the hardest diagnoses to get correct because the symptoms are rather non-specific, which may also explain why malaria-specific mortality rates from different sites in Africa vary enormously. ${ }^{43}$ Misclassification might also result from the tendency of physicians working in areas of high malaria transmission intensity to attribute most fevers to malaria. In Tanzania, for example, it has been shown in hospital data that malaria is often overdiagnosed in people with severe febrile illness. ${ }^{44}$ Because the symptoms of malaria and ARI largely overlap, VA diagnoses may simply not be accurate enough. ${ }^{16,17,45,46}$ Moreover, such inaccuracies may also be caused by a higher proportion of deaths among young children being attributable to malaria in areas of high transmission intensity. ${ }^{13-15,17,33,41}$ The likelihood of such misclassification is best shown by the fact that malaria was the main cause of death in old-aged people in this study and that most of these malaria deaths occurred in the dry season. Although, in other study areas, the same observation was made, ${ }^{24}$ this is neither plausible considering existing malaria immunity in adults living in endemic areas nor plausible in view of the very low malaria transmission intensity in the dry season. ${ }^{47,48}$

\section{CONCLUSIONS}

Reliable estimates of the burden of diseases are essential to monitor progress or pitfalls in disease control. This study provides further evidence for the high impact of malaria on mortality in the malaria endemic areas of SSA, highlights the seasonality of the disease, and supports the call for much intensified implementation of proven effective malaria control interventions. ${ }^{49}$

Received March 13, 2007. Accepted for publication July 26, 2007.

Acknowledgments: The authors thank the field staff in Nouna/ Burkina Faso and Gabriele Stieglbauer for efficient help with data management and programming.

Financial support: This work was supported by the collaborative research grant SFB 544 "Control of Tropical Infections Diseases" of the German Research Foundation (DFG), subprojects Z2 and D1.

Authors' addresses: Heiko Becher, Gisela Kynast-Wolf, Robert Ndugwa, Heribert Ramroth, and Olaf Müller, Department of Tropical Hygiene and Public Health, University of Heidelberg, Im Neuenheimer Feld 324, D-69120 Heidelberg, Germany. Ali Sié, Centre de Recherche en Santé de Nouna (CRSN), BP 02, Nouna, Burkina Faso. Bocar Kouyaté, Centre National de Recherche et de la Formation au Paludisme, 01 BP 2208, Ouagadougou 01, Burkina Faso.
Reprint requests: Heiko Becher, Department of Tropical Hygiene and Public Health, University of Heidelberg, Im Neuenheimer Feld 324, D-69120 Heidelberg, Germany, Telephone: 49-6221-565031, Fax: 49-6221-565948, E-mail: heiko.becher@urz.uni-heidelberg.de.

\section{REFERENCES}

1. Black RE, Morris SS, Bryce J, 2003. Where and why are 10 million children dying every year? Lancet 361: 2226-2234.

2. Victora CG, Wagstaff A, Schellenberg JA, Gwatkin D, Claeson M, Habicht JP, 2003. Applying an equity lens to child health and mortality: more of the same is not enough. Lancet 362 : 233-241.

3. Garenne M, Gakusi E, 2006. Health transitions in sub-Saharan Africa: overview of mortality trends in children under 5 years old (1950-2000). Bull World Health Organ 84: 470-478.

4. Lopez AD, Mathers CD, Ezzati M, Jamison DT, Murray CJ, 2006. Global and regional burden of disease and risk factors, 2001: systematic analysis of population health data. Lancet 367 : $1747-1757$.

5. Jones G, Steketee RW, Black RE, Bhutta ZA, Morris SS, 2003. How many child deaths can we prevent this year? Lancet 362 : 65-71.

6. Muller O, Krawinkel M, 2005. Malnutrition and health in developing countries. Can Med Assoc J 173: 279-286.

7. Centers for Disease Control and Prevention (CDC), 2000. Causespecific adult mortality: evidence from community-based surveillance-selected sites, Tanzania, 1992-1998. MMWR Morb Mortal Wkly Rep 49: 416-419.

8. Greenwood BM, Bradley AK, Greenwood AM, Byass P, Jammeh K, Marsh K, Tulloch S, Oldfield FS, Hayes R, 1987. Mortality and morbidity from malaria among children in a rural area of The Gambia, West Africa. Trans R Soc Trop Med Hyg 81: $478-486$

9. Greenwood BM, Bradley AK, Byass P, Greenwood AM, Menon A, Snow RW, Hayes RJ, Hatib-N'Jie AB, 1990. Evaluation of a primary health care programme in The Gambia. II. Its impact on mortality and morbidity in young children. $J$ Trop Med Hyg 93: 87-97.

10. Mathers CD, Fat DM, Inoue M, Rao C, Lopez AD, 2005. Counting the dead and what they died from: an assessment of the global status of cause of death data. Bull World Health Organ 83: $171-177$

11. Muller O, Traore C, Becher H, Kouyate B, 2003. Malaria morbidity, treatment-seeking behaviour, and mortality in a cohort of young children in rural Burkina Faso. Trop Med Int Health 8: 290-296.

12. Anker M, 1997. The effect of misclassification error on reported cause-specific mortality fractions from verbal autopsy. Int $J$ Epidemiol 26: 1090-1096.

13. Etard JF, Le Hesran JY, Diallo A, Diallo JP, Ndiaye JL, Delaunay V, 2004. Childhood mortality and probable causes of death using verbal autopsy in Niakhar, Senegal, 1989-2000. Int J Epidemiol 33: 1286-1292.

14. Korenromp EL, Williams BG, Gouws E, Dye C, Snow RW, 2003. Measurement of trends in childhood malaria mortality in Africa: an assessment of progress toward targets based on verbal autopsy. Lancet Infect Dis 3: 349-358.

15. Quigley MA, 2005. Commentary: verbal autopsies-from smallscale studies to mortality surveillance systems. Int J Epidemiol 34: $1087-1088$.

16. Snow RW, Armstrong JR, Forster D, Winstanley MT, Marsh VM, Newton CR, Waruiru C, Mwangi I, Winstanley PA, Marsh K, 1992. Childhood deaths in Africa: uses and limitations of verbal autopsies. Lancet 340: 351-355.

17. Todd JE, de Francisco A, O'Dempsey TJ, Greenwood BM, 1994. The limitations of verbal autopsy in a malaria-endemic region. Ann Trop Paediatr 14: 31-36.

18. Network INDEPTH, 2002. International Network for the Continuous Demographic Evaluation of Populations and their Health. Population and Health in Developing Countries, Volume 1: Population, Health, and Survival at INDEPTH Sites. Ottawa, Canada: International Development Research Centre.

19. Jaffar S, Leach A, Greenwood AM, Jepson A, Muller O, Ota 
MO, Bojang K, Obaro S, Greenwood BM, 1997. Changes in the pattern of infant and childhood mortality in upper river division, The Gambia, from 1989 to 1993. Trop Med Int Health 2: $28-37$.

20. Garenne M, Kahn K, Tollman S, Gear J, 2000. Causes of death in a rural area of South Africa: an international perspective. $J$ Trop Pediatr 46: 183-190.

21. Baiden F, Hodgson A, Adjuik M, Adongo P, Ayaga B, Binka F, 2006. Trend and causes of neonatal mortality in the KassenaNankana district of northern Ghana, 1995-2002. Trop Med Int Health 11: 532-539.

22. Lawoyin TO, Asuzu MC, Kaufman J, Rotimi C, Johnson L, Owoaje E, Cooper R, 2004. Using verbal autopsy to identify and proportionally assign cause of death in Ibadan, southwest Nigeria. Niger Postgrad Med J 11: 182-186.

23. Hammer GP, Some F, Muller O, Kynast-Wolf G, Kouyate B, Becher H, 2006. Pattern of cause-specific childhood mortality in a malaria endemic area of Burkina Faso. Malar J 5: 47.

24. Adjuik M, Smith T, Clark S, Todd J, Garrib A, Kinfu Y, Kahn K, Mola M, Ashraf A, Masanja H, Adazu K, Saracarlal J, Alam N, Marra A, Gbangou A, Mwageni E, Binka F, 2006. Causespecific mortality rates in sub-Saharan Africa and Bangladesh. Bull World Health Organ 84: 181-188.

25. Delaunay V, Etard JF, Preziosi MP, Marra A, Simondon F, 2001. Decline of infant and child mortality rates in rural Senegal over a 37-year period (1963-1999). Int J Epidemiol 30: 12861293.

26. de Francisco A, Hall AJ, Schellenberg JR, Greenwood AM, Greenwood BM, 1993. The pattern of infant and childhood mortality in Upper River Division, The Gambia. Ann Trop Paediatr 13: 345-352.

27. Lawoyin TO, 2001. Risk factors for infant mortality in a rural community in Nigeria. $J R$ Soc Health 121: 114-118.

28. Moore SE, 2006. Commentary: patterns in mortality governed by the seasons. Int J Epidemiol 35: 435-437.

29. Rayco-Solon P, Moore SE, Fulford AJ, Prentice AM, 2004. Fiftyyear mortality trends in three rural African villages. Trop Med Int Health 9: 1151-1160.

30. Sankoh OA, Kynast-Wolf G, Kouyate B, Becher H, 2003. Patterns of adult and old-age mortality in rural Burkina Faso. $J$ Public Health Med 25: 372-376.

31. Kynast-Wolf G, Hammer GP, Muller O, Kouyate B, Becher H, 2006. Season of death and birth predict patterns of mortality in Burkina Faso. Int J Epidemiol 35: 427-435.

32. Rowe AK, Rowe SY, Snow RW, Korenromp EL, Schellenberg JR, Stein C, Nahlen BL, Bryce J, Black RE, Steketee RW, 2006. The burden of malaria mortality among African children in the year 2000. Int J Epidemiol 35: 691-704.

33. Snow RW, Guerra CA, Noor AM, Myint HY, Hay SI, 2005. The global distribution of clinical episodes of Plasmodium falciparum malaria. Nature 434: 214-217.
34. Becher H, Kouyaté B, 2005. Health Research in Developing Countries. A Collaboration Between Burkina Faso and Germany. Heidelberg, Germany: Springer Verlag.

35. Traoré C, 2004. Epidemiology of Malaria in Rural North-Western Burkina Faso. PhD thesis, Medical Faculty, Ruprecht-KarlsUniversity, Heidelberg, Germany.

36. Greenland S, Michels KB, Robins JM, Poole C, Willett WC, 1999. Presenting statistical uncertainty in trends and dose-response relations. Am J Epidemiol 149: 1077-1086.

37. SAS Institute, 2003. SAS Version 9. Cary, NC: SAS Institute.

38. Greenwood BM, Greenwood AM, Bradley AK, Tulloch S, Hayes R, Oldfield FS, 1987. Deaths in infancy and early childhood in a well-vaccinated, rural, West African population. Ann Trop Paediatr 7: 91-99.

39. Muller O, Garenne M, Kouyate B, Becher H, 2003. The association between protein-energy malnutrition, malaria morbidity and all-cause mortality in West African children. Trop Med Int Health 8: 507-511.

40. Snow RW, Craig M, Deichmann U, Marsh K, 1999. Estimating mortality, morbidity and disability due to malaria among Africa's non-pregnant population. Bull World Health Organ 77: 624-640.

41. Morris SS, Black RE, Tomaskovic L, 2003. Predicting the distribution of under-five deaths by cause in countries without adequate vital registration systems. Int J Epidemiol 32: 10411051.

42. Rudan I, El Arifeen S, Black RE, Campbell H, 2007. Childhood pneumonia and diarrhoea: setting our priorities right. Lancet Infect Dis 7: 56-61.

43. Smith T, 2006. Commentary: malaria death rates remain highly pertinent. Int J Epidemiol 35: 704-705.

44. Reyburn H, Mbatia R, Drakeley C, Carniero I, Mwakasungula E, Mwerinde O, Saganda K, Shao J, Kitua A, Olomi R, Greenwood BM, Whitty CJ, 2004. Overdiagnosis of malaria in patients with severe febrile illness in Tanzania: a prospective study. BMJ 329: 1212.

45. Chandramohan D, Setel P, Quigley M, 2001. Effect of misclassification of causes of death in verbal autopsy: can it be adjusted? Int J Epidemiol 30: 509-514.

46. English M, Punt J, Mwangi I, McHugh K, Marsh K, 1996. Clinical overlap between malaria and severe pneumonia in Africa children in hospital. Trans $R$ Soc Trop Med Hyg 90: 658-662.

47. Greenwood BM, Bojang K, Whitty CJ, Targett GA, 2005. Malaria. Lancet 365: 1487-1498.

48. Traoré C, 2004. Epidemiology of Malaria in Rural North-Western Burkina Faso. Heidelberg, Germany: Medical Faculty, Ruprecht-Karls-University.

49. Kouyaté B, Sie A, Yé M, De Allegri M, Müller O, 2007. The great failure of malaria control in Africa: a district perspective from Burkina Faso. PLOS Med 4: e127. 